\title{
Achieving socio-cultural sustainability in the design of the government-sponsored single family houses in the UAE: the case of Al Ain
}

\author{
K. Galal-Ahmed \\ Architecture Engineering Department, College of Engineering, \\ UAE University, Al Ain, UAE
}

\begin{abstract}
Many government-sponsored single family houses have been built in the UAE during the last few years. Given the importance of achieving sustainability in the housing sector, the question which poses itself is: are these houses socioculturally sustainable? Al Ain city has been selected for undertaking some relevant case studies of this type of housing. After building a conceptual framework for the qualitative analysis, some research tools were applied including semi-structured interviews with residents, design analysis and Space Syntax analysis. Through these multi phases analyses a clearer understanding of the social and cultural suitability of the design of the government-sponsored single family houses in Al Ain, has been realized fulfilling the first objective of the research. Consequently, relevant design guidelines that help in achieving social and cultural sustainability of this type of housing have been reached fulfilling the second objective of the research.
\end{abstract}

Keywords: social, cultural, sustainability, housing, UAE, Al Ain.

\section{Introduction}

Of the three pillars of sustainable development, social sustainability is perhaps the least explored within the mainstream development literature. Initially, the intellectual debate on sustainability was confined to two of its basic dimensions: economic sustainability and environmental sustainability. As a result, sociocultural sustainability has been the aspect of development that tends to be neglected in public policy initiatives [1]. The focus of this research is very much on the dynamics within the social and cultural spheres of sustainability. The 
objective of the research is two folds. First, it aims at investigating the social and cultural suitability of current government-sponsored patterns of single family houses in Al Ain. Second, it aims at proposing design guidelines that help realizing socio-culturally sustainable public housing in UAE in general.

The research is a qualitative research that employs multiple research tools. It began with investigating the concepts of social and cultural sustainability and then situated them within the housing context. The qualitative approach was selected to help probing, in-depth, the social features of the governmentsponsored single family houses in Al Ain. Professionally designed patterns for single family houses were selected to be the scope of the research as it is believed to be the much more desirable housing patterns for UAE citizens in general and the residents in $\mathrm{Al}$ Ain in specific. Case studies of relevant housing designs in $\mathrm{Al}$ Ain are to be analyzed in terms of their suitability for the dwellers' socio-cultural values. Triangulation of Data was realized through the utilization of multiple analyses. First is a professional analysis where the researchers as, architects, analyze the design drawings to investigate the variables manifested in the case study house design. Second is face-to-face questionnaires administered with residents of the selected case studies. This was an essential tool of analysis for the indicators of socio-cultural sustainability. Third, is the application of Space Syntax relevant software packages as an essential tool in the evaluation of some indicators such as integration, visibility and permeability of spaces $[2,3]$.

\section{A conceptual framework for socio-cultural sustainability principles}

Social sustainability according to Barnett and Buys [4] includes the features of the house that were considered to lower the risks of injury, improve safety and security, and enhance livability and family life. They argue that the results of some experimental projects have demonstrated that there are significant benefits to family living from sustainable housing, assessed through the feedback from residents. Many design features and products improved safety, comfort, and livability. As mentioned earlier, this research aims to identify, and then test, the key principles of socio-cultural sustainability and their indicators for the case of UAE, with special reference to $\mathrm{Al}$ Ain. The work of Chiu $[5,6]$ was the main core for identifying the principles of socio-cultural sustainability in housing. Based on this work and other relevant literature [7-12] eight principles for social and cultural sustainability in houses were identified (table 1). Indicators of sustainable urban housing are essential if effective sustainable housing policy is to be implemented. One definition of urban sustainability indicators is that they are 'bellwether tests of sustainability and reflect on something basic and fundamental to the long term economic, social or environmental health of a community over generations' [13]. Table 1 illustrates the principles, indicators and variables of socio-cultural sustainability which are going to be utilized in the case studies using the mentioned above three measuring methods: analysis of architectural designs, questionnaires with residents and relevant Space Syntax software packages. 
Table 1: Principles, indicators and variables of socio-cultural sustainability.

\begin{tabular}{|c|c|c|}
\hline Principles & Indicators & Variables \\
\hline $\begin{array}{c}1- \\
\text { Responsiveness } \\
\text { to social needs }\end{array}$ & $\begin{array}{c}1-1 \text { Needed } \\
\text { functional spaces }\end{array}$ & $\begin{array}{c}\text { 1-1-1 Suitable number of rooms per person } \\
\text { 1-1-2 Suitable service facilities (toilets, stores, etc). } \\
1-1-3 \text { Need for a garden. } \\
\text { 1-1-4 Need for a balcony or terrace. } \\
\text { 1-1-5 Suitable areas for functional spaces. } \\
\text { 1-1-6 Suitable functional spatial organization. } \\
\text { 1-1-7 Preferred number of floors. }\end{array}$ \\
\hline $\begin{array}{l}2- \\
\text { Responsiveness } \\
\text { to cultural } \\
\text { values }\end{array}$ & $\begin{array}{l}\text { 2-1 Increased social } \\
\text { cohesion and } \\
\text { integrity } \\
2-2 \text { Privacy } \\
\\
\text { 2-3 Customs } \\
\text { 2-4 Continuation of } \\
\text { folk art and } \\
\text { architecture } \\
\text { 2-5 Preservation of } \\
\text { housing design } \\
\text { heritage }\end{array}$ & $\begin{array}{l}\text { 2-1-1 Relationship among spaces } \\
\text { 2-2-1 Isolation of servants (Insulation). } \\
\text { 2-2-2 Relationship with visitors. } \\
\text { 2-2-3 Orientation of the house and locations of } \\
\text { fenestrations in relation to surrounding houses. } \\
\text { 2-2-4 Entrances (Residents-Visitors). } \\
\text { 2-3-1 Kitchen and dining location. } \\
\text { 2-4-1 Manifestation of collective memory of UAE } \\
\text { people both internally and externally through, for } \\
\text { example, architectural motives in housing design. } \\
\text { 2-5-1 Functions and their distribution that are derived } \\
\text { from heritage design and need to be preserved in } \\
\text { contemporary live. }\end{array}$ \\
\hline $\begin{array}{l}\text { 3- Quality of } \\
\text { life }\end{array}$ & $\begin{array}{l}\text { 3-1 Healthy indoor } \\
\text { environment. (Clean } \\
\text { air, water and soil) } \\
\text { 3-2 Good sense of } \\
\text { place }\end{array}$ & $\begin{array}{l}\text { 3-1-1 Building orientation in relation to the north } \\
\text { direction and sun path. } \\
\text { 3-1-2 Treatment of noise pollution and air pollution. } \\
\text { 3-1-3 fittings resisting insects. } \\
\text { 3-2-1 Providing good views to green areas (gardens). } \\
\text { 3-2 -2 Easy movement due to the open design. }\end{array}$ \\
\hline 4- Adaptability & $\begin{array}{l}\text { 4-1 Responsiveness } \\
\text { to individual } \\
\text { preferences } \\
\text { 4-2 Ability for } \\
\text { changing } \\
\text { functions/areas } \\
\end{array}$ & $\begin{array}{l}\text { 4-1-1 Design allows for redistribution of spaces } \\
\text { functions/areas. } \\
\text { 4-2-1 Design allows for change of spaces } \\
\text { functions/areas over time. } \\
\text { 4-2-2 Design allows for adding more floors/spaces. }\end{array}$ \\
\hline 5- Safety & $\begin{array}{l}\text { 5-1Protection from } \\
\text { hazards }\end{array}$ & $\begin{array}{l}\text { 5-1-1 Means of fire resistance in design. } \\
\text { 5-1-2 Anti slippery floorings. } \\
\text { 5-1-3 Means of escape in case of emergency. }\end{array}$ \\
\hline 6- Security & $\begin{array}{l}\text { 6-1 Protection from } \\
\text { strangers (crimes) }\end{array}$ & $\begin{array}{l}\text { 6-1-1 Means of security in design details. } \\
\text { 6-1-2 Relative position for each room in plan. } \\
\text { 6-1-3 Degree of visibility. }\end{array}$ \\
\hline 7- Participation & $\begin{array}{l}\text { 7-1 Taking part in } \\
\text { decision-making }\end{array}$ & $\begin{array}{l}\text { 7-1-1 Participate in the selection of site and area. } \\
\text { 7-1-2 Participate in the design of the house. } \\
\text { 7-1-3 Participate in building the house. } \\
\text { 7-1-4 Participate in constructing alterations. }\end{array}$ \\
\hline $\begin{array}{l}\text { 8- Accessibility } \\
\text { (Inclusive/ } \\
\text { Universal } \\
\text { Design) }\end{array}$ & $\begin{array}{l}\text { 8-1 Suitability for } \\
\text { elderly }\end{array}$ & $\begin{array}{l}\text { 8-1-1 Accessible primary building entrance. } \\
\text { 8-1-2 Suitable vertical circulation means for elderly. } \\
\text { 8-1-3 Level threshold to each room. } \\
\text { 8-2-1 Primary entrance and common use area doors } \\
\text { must be accessible. Secondary doors must be useable } \\
\text { by persons in wheelchairs. } \\
\text { 8-2-2 Light switches, electrical outlets, thermostats } \\
\text { and other control devices in accessible locations. } \\
\text { 8-2-3 Kitchens and bathrooms must be designed to } \\
\text { be useable by persons in wheelchairs. } \\
\text { 8-2-4Suitable parking space width and access }\end{array}$ \\
\hline
\end{tabular}




\section{Analysis of the selected design models}

Five design models have been selected for analysis in Al Ain (called in this research as Types A, B, C, D and E). The design models actually share most of the design characteristics with some diversity in areas and services. These housing prototypes were built by the UAE government mostly in the 1990s and $\operatorname{mid} 2000 \mathrm{~s}$ [14].

Type A: Type A housing model consists of two separated blocks. The front block contains the guests' related activities; majlis, dining, toilets and hand wash. This block contains in its rear part the main kitchen, store room, servant room with toilet and electricity room. The rear block contains the family activities divided in two floors. The ground floor contains the family hall, bedrooms, bathroom, kitchenette and hand wash. The first floor contains two bedrooms with a toilet and one master bedroom. This prototype was usually built on $45 \mathrm{~m} \mathrm{x} 45 \mathrm{~m}$ plots with a total built up area of $431 \mathrm{~m}$. sq.

Type B: This model consists of two story compact block containing all family, guest and service activities. The house is built on a $45 \mathrm{~m}$. sq. plot. The first floor consists of a main entrance leading to the guest area containing majlis, dining, hand wash and a toilet. The main entrance also leads to the family activities area containing family living, toilet and one bedroom with a toilet. Attached to the family zone is the service zone which is separated from the family zone by a corridor. The service zone contains the main kitchen, store, electricity room, maid's room and maid's toilet. The first floor contains 4 bedrooms, 2 bathrooms and 1 master bedroom. The total built-up area of this type is about $495 \mathrm{~m}$. sq.

Type $\boldsymbol{C}$ : This is one floor housing model consists of three masses on a $24.4 \mathrm{~m}$ $\mathrm{x} 33.5 \mathrm{~m}$ plot. The main mass is allocated for family activities and contains a family hall, 4 bedrooms, 1 master bedroom with a toilet and 2 toilets. The guest mass contains majlis, dining, hand wash and a toilet. The third mass is the service mass encompassing the main kitchen, a store and the maid's room with a maid's toilet. The total built up area is about $405 \mathrm{~m}$. sq.

Type D: Like model C, Model D also consists of three separated masses the family mass; the guest mass and the service mass. This model is built over a 45 m. x $45 \mathrm{~m}$. plot. The family mass consists of two floors and contains in the ground floor majlis, dining, hand wash, toilet and guest bedroom with a toilet. The first floor of this mass contains master bedroom, 2 bedrooms, a bathroom and hand wash. A new design item appeared in both the ground and first floors of the family facilities mass and in guest mass as well. This is the lewan. The second mass contains the guest facilities; majlis, dining, hand wash and a toilet. Total built up area of this model is about $490 \mathrm{~m}$. sq.

Type E: This type is an extented version of Type A. It is built on a $45 \mathrm{~m} \mathrm{x} 45$ $\mathrm{m}$ plot with a built up area of about $498 \mathrm{~m}$. sq. Compared to Type A, the ground floor has an extra bedroom and a larger family hall. The first floor contains two bathrooms and one master bedroom. Figure 1 shows the plans of Type A housing model which represents the most prevailing single family public housing type. 

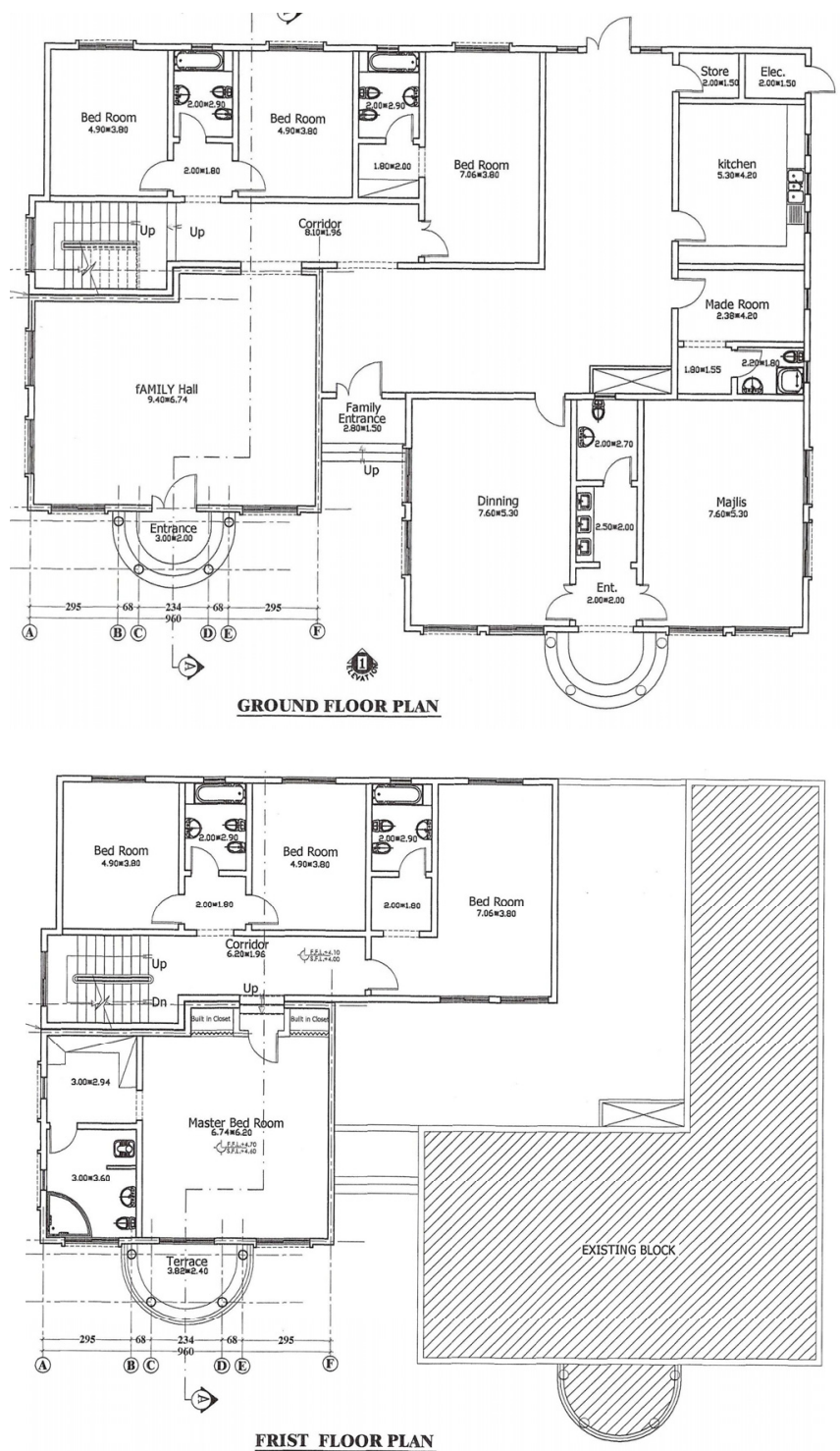

Figure 1: $\quad$ Plans of type a housing model.

\section{Results of the qualitative evaluation of socio-cultural sustainability in the selected design models}

In the following section, fig.2, the degree of achievement of each of the social and cultural sustainability principles, through applying the above variables and indicators, table 1, was assessed through the implementation of the three adopted methods, architecture design analysis, responses to the questions of the 
questionnaire distributed on 60 families and finally the Space Syntax software applications. The evaluation was based on the following qualitative scale:

Achieved

Significantly Achieved
Partially Achieved

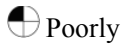

Achieved $\bigoplus$ Not

Achieved

\subsection{Evaluation of the 1st Principle}

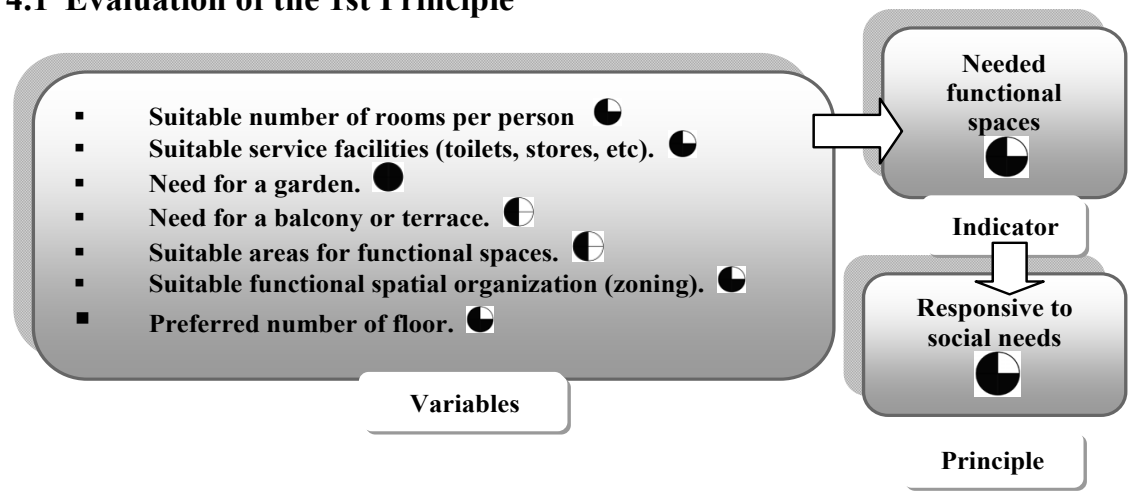

\subsection{Evaluation of the 2nd Principle}

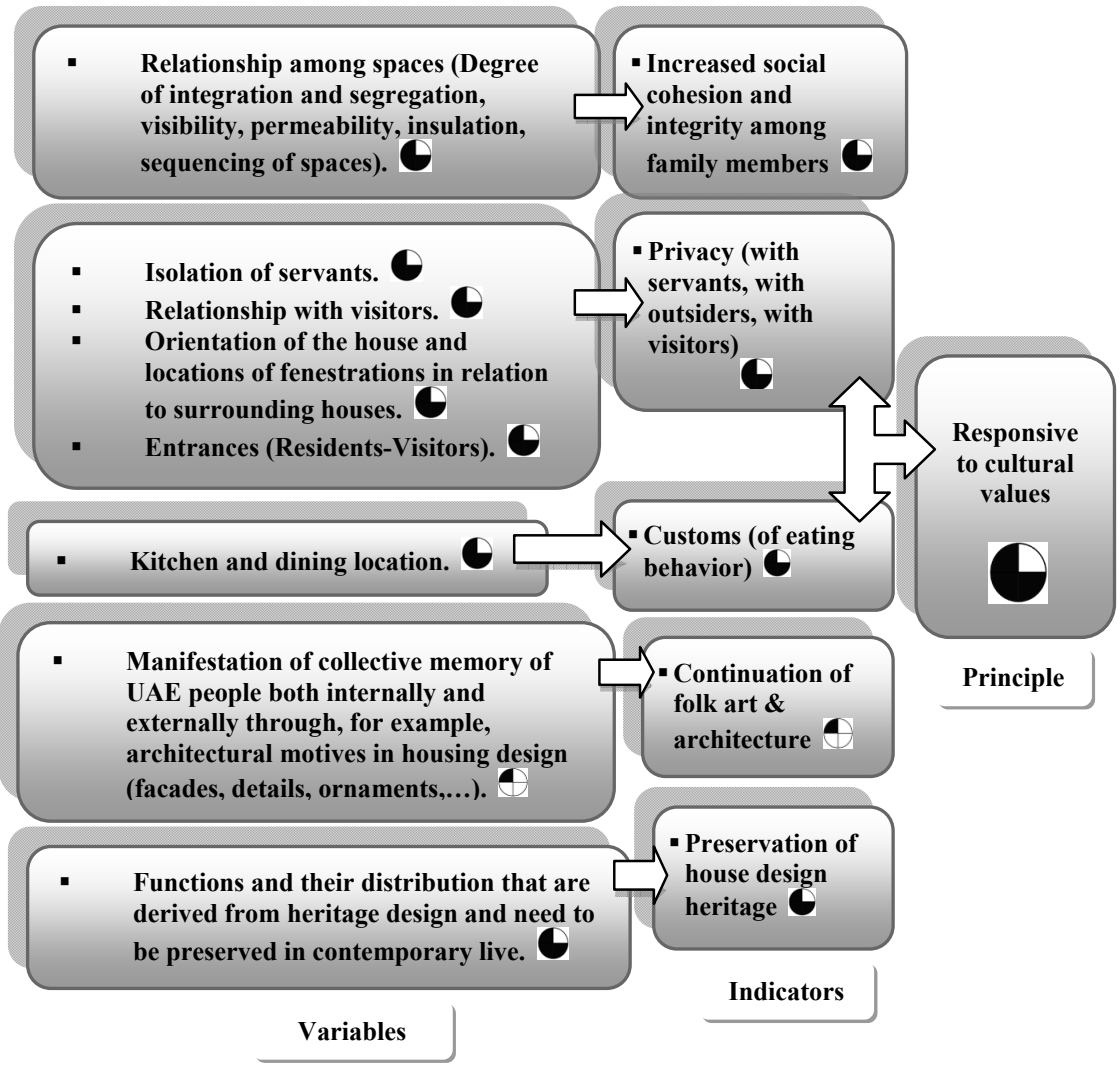




\subsection{Evaluation of the 3rd Principle}

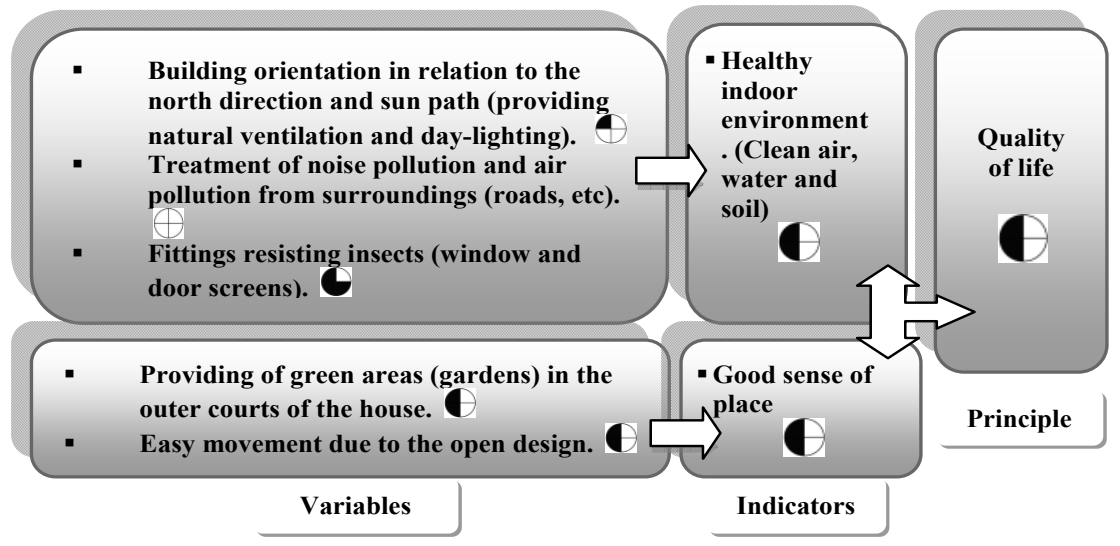

\subsection{Evaluation of the 4th Principle}

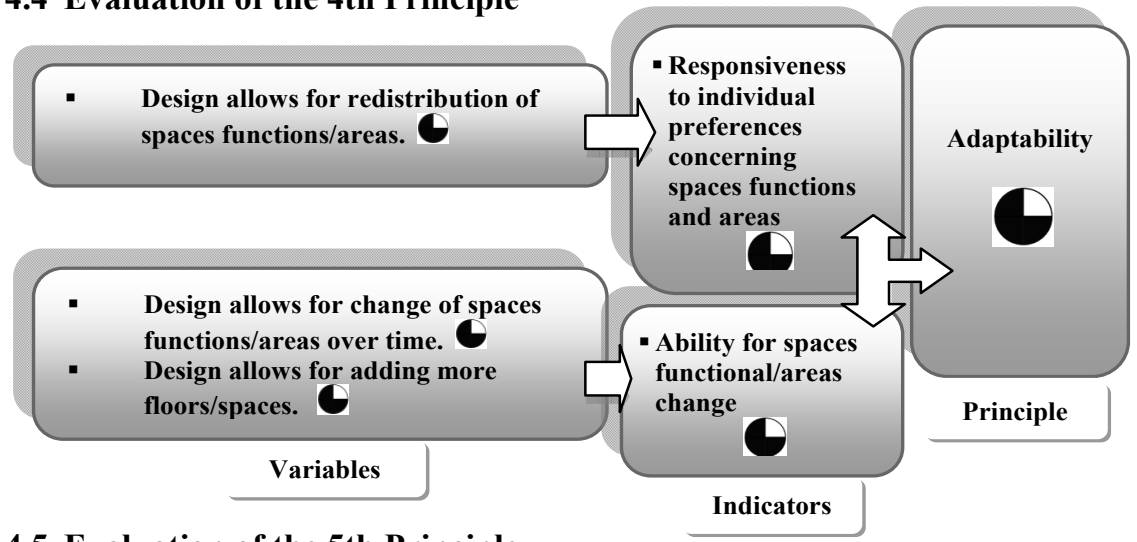

\subsection{Evaluation of the 5th Principle}

to individual

preferences concerning paces function and areas 


\subsection{Evaluation of the 7th Principle}

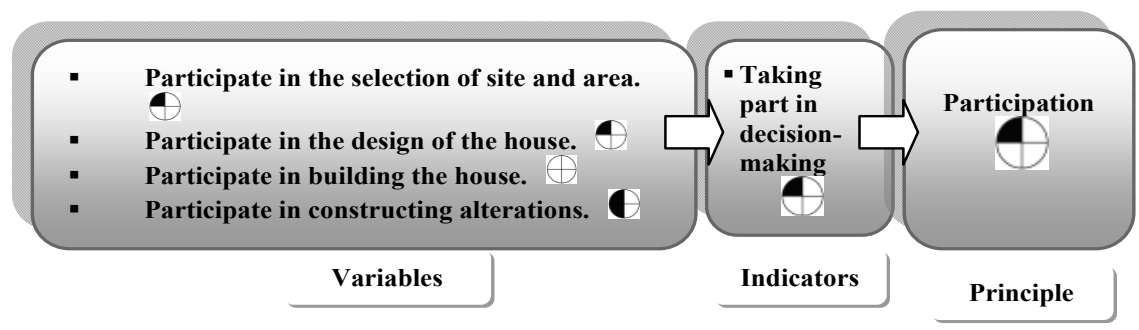

\subsection{Evaluation of the 8th Principle}

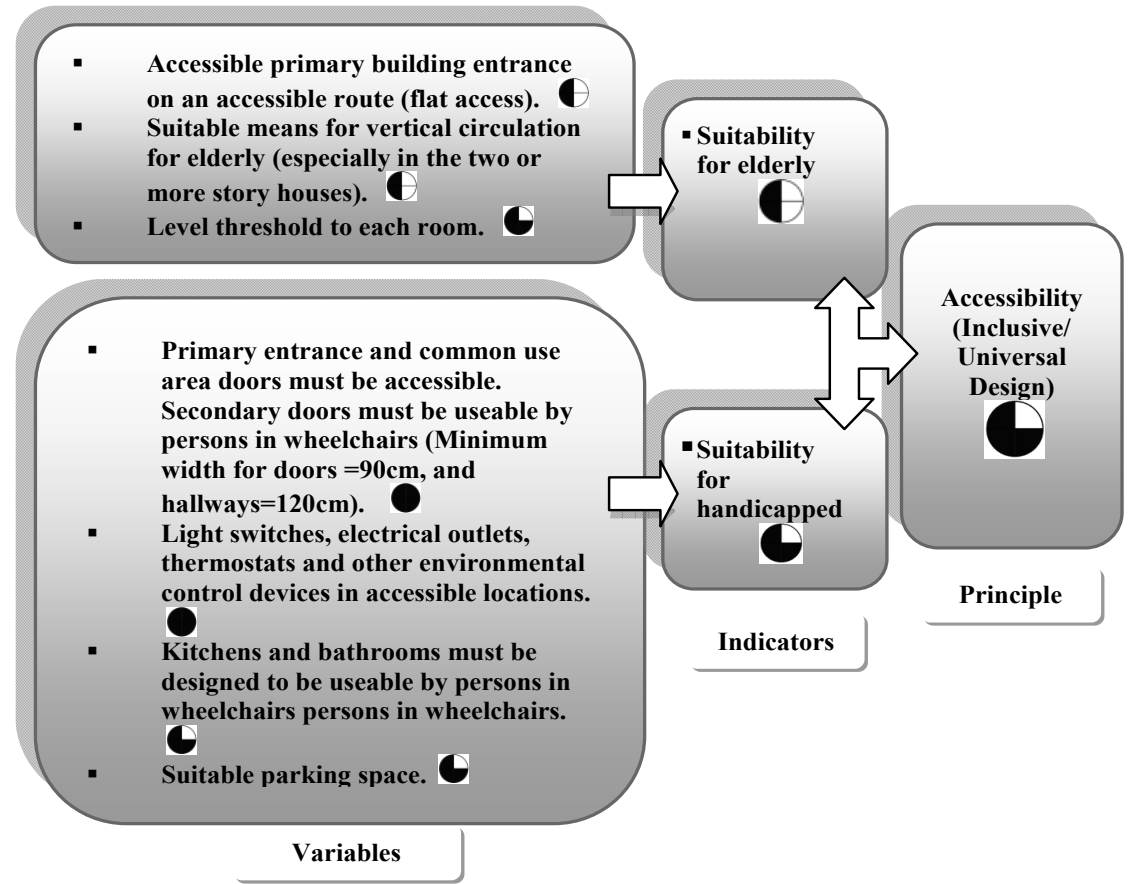

Figure 2: Evaluation of the degree of achievement of the social and cultural sustainability variables, indicators and principles.

To conclude, the research multiple investigations using the three main tools, the design analysis, the questionnaire and Space Syntax software packages, has found that 4 out of the 8 principles of socio-cultural sustainability in housing have been significantly achieved. These principles are; "responsiveness to social needs", "responsiveness to cultural needs", "adaptability", "Accessibility". Two principles have been found to be partially achieved. These are; the "quality of 
life" and "security". The two remaining principles, namely, "safety" and "participation" have been found to be poorly achieved.

\section{Proposed design guidelines for achieving socio-cultural sustainability in public housing in Al Ain}

Based on the findings of the research about evaluating socio-cultural sustainability in public housing in Al Ain the research, in order to achieve its second objective, is proposing new design guidelines for achieving socioculturally sustainable public housing in Al Ain, and UAE in general. This proposed design guidelines are subsumed into 8 categories representing the 8 socio-cultural sustainability principles.

First, for achieving "responsiveness to social needs", the needed functional spaces should be tackled. It seems that the idea of having an expandable house (such as in the case of Types A and E) sounds applicable and practical. The house can begin with 5 bedrooms and allows the residents to increase this number, if and when needed, incrementally either horizontally or vertically under the permission and supervision of the municipality. Concerning suitable number of service facilities, the current rate of having a bathroom for each two bedrooms, 1 bathroom for the master bedroom, 1 toilet and hand wash for serving guests and similar numbers for serving family hall, 1 main kitchen, a maid's room and a driver's room with toilets seems suitable in general in terms of numbers. Nonetheless with the idea of expansion, increasing the number of facilities might need to be considered. In addition, each house should have a garden as this looks an essential need for residents. While the design should encompasses terraces and balconies it should, at the same time, allow the residents to modify their terraces and balconies to be part of the internal spaces. Current areas for family living, majlis and dining (about $4 \mathrm{~m} \times 6 \mathrm{~m}$ ) should be increased to suit the social events and gatherings. Separating the majlis and dining for guests as well as separating the service facilities, to some extent, from the family zone sound desirable. So the compactness of the main three zones (family, guests, services) should be avoided or at least dealt with in a way that create some actual isolation between guests zone and family zone and to create some isolation between family zone and service zone. Finally, a design for two floors house or one floor that can be expanded to two is recommended.

Second, for Achieving "responsiveness to cultural values" a number of issues should be addressed. Social cohesion and integrity among family members: more integration and visibility should be achieved in family zone by avoiding single or double loaded corridors for rooms gathering to increase social cohesion and integrity among family members.

Privacy: house design should achieve privacy on multiple levels. First, there should be privacy to family members as well as guests and servants from outsiders. This can be achieved through careful orientation of the house masses in relation to its surroundings, careful design of external fences, careful design of landscape elements such as trees and careful technical treatment for windows especially in the upper floors, such as using mirror glass. The second level is the 
privacy of family members from guests. This can be achieved through careful positioning of doors and windows to prevent direct visual corridors and separating entrances for guests and family members.

Customs (of eating behavior): the main kitchen should be positioned outside the main family zone but it should be easily accessible from it as well. Other small family kitchenette should be provided in the family hall to serve family members easily for quick snacks and drinks.

Continuation of folk art and architecture: the house design needs to reflect the collective memory of UAE people both internally and externally through utilization of modern treatment of traditional architectural motives that can be manifested in house facades, and details of windows, doors and internal ornaments.

Preservation of housing design heritage: house design should be affected by the continuous elements of traditional Emirati house especially the majlis and dining for guests. It should also have an inner collective space surrounded by house zones (masses).

Third, for achieving "quality of life" two points are illustrated. Healthy indoor environment: house design should provide good day lighting and natural ventilation through building orientation in relation to the north direction and sun path. Sources of noise pollution and air pollution from surroundings, such as roads, should be treated in design through, for example, using well-sealed double glazing fenestrations and thermally and acoustically isolated building envelop. Achieving healthy indoor environment also necessitates providing fittings and elements that resist insects especially on windows and doors such as mesh screens and insect resisting plants.

Good sense of place: house design should pay attention, not only to the provision of green areas (gardens) in the outer courts of the house, but to having good landscape for them. Good sense of place can also be intensified internally by considering ease of movement internally by adopting open design approach, when appropriate.

Fourth, for achieving "adaptability" the following points should be addressed. Responsiveness to individual preferences: house design should allow for redistribution of functions/areas of inner spaces based on individual preferences. This needs a good deal of flexibility measures on the part of the design and the structure system.

Ability for changing functions/areas over time: as residents' needs are changing over time the design of the house should help accommodating these changes. For example, dropped beams between spaces should be avoided and movable partitions can be used instead of the fixed conventional cement brick ones. Also the design structure should allow for adding more floors and/or spaces.

Fifth, is achieving "safety" through Protection from hazards. House design should include suitable means of fire resistance such as fire resistant doors in kitchens, smoke detectors and smoke alarms in each space. Anti slippery floorings in both internal and external spaces should be adopted in design. 
Escape in emergency cases should be studied in design. For example, the opening direction of the side and main entrances should allow for escape.

Sixth, is achieving "security" through Protection from crimes. Design should provide means for fighting crimes from outsiders. This could be achieved through proper design for external fences, appropriate building materials, lockers, alarms and sensor lighting. Rooms and halls should have relative positions that allow for visual control for each room in plan. The design should also provide good degree of visibility from within the house to the outside court.

Seventh, achieving "participation" should be realized through residents' involvement in design decision-making. Residents should be given the opportunity for genuine participation in the whole processes of the design and construction of their houses. This includes participation in the selection of the site and area of the house plot, in the design and building of houses and in conducting addition and/or alterations of inner spaces. Participation in the design of the house can be realized through the ability to select among alternatives that are all adaptable and responsive to future unavoidable changes.

Eighth, for achieving "accessibility (inclusive/universal design)" two crucial issues need to be considered. Accessibility for elderly: the design of the house has a lot to offer to provide a barrier free and fully accessible house facilities for elderly residents. This can be achieved through design measures such as avoiding entrance staircases (flat access), suitable means for vertical circulation for elderly without need for a full equipped lift. Instead stare lifts that require a specific design for the handrail and the shape of the staircase can achieve that. Lofted threshold in each room and bathrooms should also be avoided.

Accessibility for handicapped: the design also should take into consideration the cases where handicapped residents might face in their daily domestic activities. The accessibility of primary entrances and the doors of commonly used areas (especially for wheelchair users) should be considered. For secondary doors to be useable by persons in wheelchairs the minimum width for doors should be larger or equal to $90 \mathrm{~cm}$, and hallways should be larger or equal to 120 $\mathrm{cm}$. Light switches, electrical outlets, thermostats and other environmental control devices should be designed to be in accessible locations. Kitchens and bathrooms must be designed to be useable by persons in wheelchairs persons in wheelchairs. Finally, car parking should be designed according to suitable parking space width and access for wheelchair users.

\section{Conclusion}

The research tackled the very important issue of socio-cultural sustainability in public housing in Al Ain. The research defined and then evaluated 8 main principles for socio-cultural sustainability in housing in Al Ain. It has been found that 4 out of these 8 principles have been significantly achieved. These principles are; "responsiveness to social needs", "responsiveness to cultural needs", "adaptability", "Accessibility". Two principles have been found to be partially achieved. These are; the "quality of life" and "security". The two remaining principles, namely, "safety" and participation have been poorly achieved. Based 
on the findings of the research about evaluating socio-cultural sustainability in public housing in 1 Ain the research, in order to achieve its second objective, is proposing new design guidelines for achieving socio-culturally sustainable public housing in Al Ain, and UAE in general. This proposed design guidelines are subsumed into 8 categories representing the 8 socio-cultural sustainability principles.

\section{References}

[1] Brisbane Institute, Social Sustainability: The Missing Dimension Report, The Brisbane Institute: Queensland, 2006.

[2] Sanli, S., Dursun, P. \& Saglamer, G., Decoding Houses of a Turkish Architect, Proc. of the 6th international space syntax symposium, Istanbul, 2007.

[3] Hillier, B. and Hanson, J., Social Logic of Space, University Press: Cambridge, 1984.

[4] Barnett, K. \& Buys, L., Tenants' Evaluation of Experiences of Social Sustainability within the Home Environment, Final Report, Department of Public Works and the Department of Housing (Queensland), Queensland University of Technology (QUT), and Centre for Social Change Research (CSCR): Australia, 2005.

[5] Chiu, R. L., Socio-Cultural Sustainability of Housing: a Conceptual Exploration, Housing Theory and Society, 21, pp 65-76, 2004.

[6] Chiu, R. L., Sustainable development: a new perspective for housing in Hong Kong. Proc. of the 21st Century: Challenge and Commitments Conf., Hong Kong Housing Authority, Hong Kong, 2004b.

[7] McKenzie, S., Social Sustainability: Towards Some Definitions, Hawke Research Institute, Working Paper Series No 27, Hawke Research Institute, University of South Australia: Australia, 2004

[8] Mohammad, F. \& Amato, A., Public Housing and Social Sustainability Indicators: HK-BEAM as a Case Study, Proc. of the COBRA 2006 The Annual Research Conference of The Royal Institution of Chartered Surveyors, London: University College London 7-8 September 2006

[9] Barron L. \& Gauntlett, E., WACOSS Housing and Sustainable Communities Indicators Project. Stage 1 Report - Model of Social Sustainability. http://www.wacoss.org.au/index.php?option=displaypage \&Itemid=421\&op=page, 2002.

[10] Fletcher, V., Designing for Life: Inclusive Residential Design for Socially Sustainable Communities, Proc. of the Housing Washington 2008 Symposium, Washington: Institute for Human Centered Design, 2008.

[11] Buys, L., Barnett, K., Miller E., \& Bailey, C., Smart Housing and Social Sustainability: Learning from the Residents of Queensland's Research House, Australian Journal of Emerging Technologies and Society, 3(1), pp. 43-57, 2005.

[12] European Sustainable Trade Forum, Management of Sustainability, http://www.gdrc.org 
[13] Nessa, W., On indicators of Sustainable Housing in the European Urban Context, Proc. of the ENHR 2006 Conference, Ljubljana, Slovenia, 2006.

[14] Al Ain Municipality, Al Ain Housing Projects, http://www.am.ae 